\title{
APUNTES DE CRÍTICA TEXTUAL A EL SEÑOR FEUDAL (1896), DE JOAQUÍN DICENTA
}

\author{
TEXTUAL CRITICISM NOTES ON JOAQUÍN DICENTA'S \\ EL SEÑOR FEUDAL (1896)
}

\author{
Manuel Javier Muñoz Álvarez \\ Universidad de Málaga \\ majamual@gmail.com
}

Fecha de recepción: 03-12-2020

Fecha de aceptación: 17-08-2021

\section{RESUMEN}

A finales de 1896, se estrenó El señor feudal, un drama social compuesto por Joaquín Dicenta, que acabó olvidado por la apabullante acogida de Juan José (1895), su predecesor. Este artículo aborda las principales transformaciones que ha experimentado la obra en su transmisión textual, tanto las variantes de autor como los accidentes de la copia, en base a los dos manuscritos conservados y la editio princeps. Un estudio de este tipo permite obtener un retrato más fidedigno del escritor y entender mejor su proceso creativo, además de llenar algunas de las lagunas que rodean a esta obra ignorada por gran parte de la crítica.

Palabras Clave: Joaquín Dicenta; El señor feudal; drama social; crítica textual; variantes

\section{ABSTRACT}

At the end of 1896, El señor feudal was performed for the first time. Joaquín Dicenta wrote this social drama, which was forgotten due to the overwhelming reception of the previous play: Juan José (1895). This article deals with the main changes in El señor feudal in its textual transmission, both the author's variants and the mistakes inserted in the copy, 
based on the two manuscripts conserved and the editio princeps. This sort of study allows for a more reliable portrait of the writer and a better understanding of his creative process. In addition, it also fills some of the gaps that surround this play that has been overlooked by the vast majority of critics.

Keywords: Joaquín Dicenta; El señor feudal; social drama; textual criticism; variants

No cabe duda de que una de las figuras más singulares de la bohemia madrileña de finales del siglo XIX fue la de Joaquín Dicenta ${ }^{1}$. El escritor bilbilitano cultivó todos los géneros a lo largo de su prolífica trayectoria, pero su nombre ha pasado a nuestra historia literaria por haber desempeñado un papel importante en la aclimatación de un movimiento teatral que en ese momento histórico estaba triunfando en las tablas europeas: el drama so$\mathrm{cial}^{2}$. Esta corriente se caracterizaba, en sentido amplio, por convertir en materia teatral la lucha de clases (TORRENTE BALLESTER, 1957: 60). Su adaptación española ofrecía algunas peculiaridades, como «la incorporación complementaria de contenidos melodramáticos o sentimentales» (FERNÁNDEZ INSUELA, 1997: 16-17) en la presentación del conflicto. Por eso «el choque de clases, cada una con su problemática socioeconómica es, en realidad, menos un choque de clases, stricto sensu, que un choque de personas morales» (RUIZ RAMÓN, 2011: 363).

Dicenta se convirtió en el buque insignia de este nuevo subgénero con tan solo cuatro títulos: Juan José (1895), El señor feudal (1896), Aurora (1902) y Daniel (1907). Según McGrath (2004: 236), estos dramas protagonizados por las verdaderas víctimas de la sociedad constituyeron la aportación más valiosa de Dicenta al panorama teatral. En contra de la postura tradicionalmente aceptada, Peral Vega (2008: 70) ha especificado «que Juan José y Aurora pueden ser considerados meros melodramas en los que late, al fondo, la confrontación social entre clases, frente a El señor feudal y Daniel, estos sí dramas sociales en el sentido estricto del término, por cuanto la denuncia explícita de la injusticia que media entre estratos diversos de la sociedad soporta, de principio a fin, el conflicto dramático». Por su parte, Paco de Moya (1971-1972: 142) ha defendido que El señor feudal, además de un drama social, podría clasificarse perfectamente dentro de otro subgénero teatral en boga durante el período de entresiglos: el drama rural. A pesar de que uno y otro persiguieran distintas intenciones, algunas veces sus caminos se entrecruzaron, como bien demuestran la obra que se analiza y El labrador de más aire (1937), de Miguel Hernández.

En este artículo analizaré las transformaciones que $\mathrm{El}$ señor feudal ${ }^{3}$ ha experimentado en su transmisión, tanto las variantes motivadas por la voluntad del autor como aquellos

1 Ríos Carratalá (2019: 267-280) ha estudiado la reputación que el bilbilitano consiguió labrarse en su época, señalando las variadas reacciones que su controvertida personalidad suscitó entre sus coetáneos, algunos de los cuales lo consideraron una «calamidad nacional».

2 La crítica especializada ha empleado, con mayor o menor acierto, una gran variedad de marbetes para denominar esta corriente teatral. Además de la referida, se han utilizado «drama socialista», «drama realista»o «drama naturalista» (GIES, 1996: 42).

3 A diferencia de Juan José, El señor feudal fue acogido con tibieza. José Martínez Ruiz manifestó su decepción en estos términos: «No hay grandiosidad, vigor, en la obra. Es una obra escrita deprisa, sin observación 
accidentes ocasionados durante la copia. Me he centrado en esta comparación debido a la importancia de Dicenta y a la poca atención concedida por los especialistas de su obra. Las investigaciones concernientes al drama son escasas si se compara su número con el de los trabajos dedicados a Juan José. No es de extrañar que siga habiendo aspectos apenas estudiados por la crítica. Además, un análisis de este tipo contribuye a comprobar la evolución del proceso creativo de un autor y, por lo tanto, a entender desde otra perspectiva las idiosincrasias de su imaginario y de su estilo.

En este caso, he decidido cotejar tres versiones distintas de El señor feudal, todas de 1896: el manuscrito de la Biblioteca del Instituto del Teatro de Barcelona (desde ahora lo llamaré $A$ ), el manuscrito de la Biblioteca Nacional $(B)$ y la editio princeps publicada en Madrid $(C)^{4}$. En un futuro compararé $C$ con el resto de las ediciones impresas. Ahora voy a reconstruir la historia de la transmisión de cada uno de los textos y la examinatio de las principales variantes, con el objeto de intentar explicar las razones que condujeron al autor a cambiar pasajes muy concretos de su pieza dramática.

En la fontes criticae, la fase inicial de la recensio, descubrí que la prensa decimonónica había registrado por entero el proceso de escritura de El señor feudal hasta su estreno la noche del 2 de diciembre de 1896 en el Teatro de la Comedia de Madrid ${ }^{5}$, lo que demuestra que el público aguardó con expectación al heredero de Juan José. En líneas generales, puede decirse que el 10 de julio de 1896 Dicenta había proyectado escribir El señor feudal para el actor y director Emilio Mario (FILEMÓN, 1896: 2). Tres meses después, en

ninguna de la realidad, para salir del paso y cobrar unos cuartos» (ap. RÍOS CARRATALÁ, 2019: 271). García Pavón cree que «el tenue dibujo del artista [en Juan José] ha sido sustituido por el tiralíneas del artesano [en El señor feudal]» (1962: 50-51). A mi parecer, el éxito descomunal de su predecesora ha ensombrecido las virtudes de El señor feudal. Luis Gabaldón (1896: 7) hizo notar en su reseña lo odioso de las comparaciones: «Que la obra no es un Juan José, dicen. ¡Naturalmente! ¿Cómo ha de serlo, si el ambiente en que se mueven los personajes de $E l$ señor feudal es distinto, si sus pasiones, si sus sentimientos son otros, si es otra la tendencia y el procedimiento?». Con todo, Dicenta estaba menos familiarizado con el campo que con la ciudad (HALL, 1952: 59); opinión similar a la de Martínez Ruiz, que criticaba a Dicenta por haber hecho coincidir en El señor feudal la trilla con la vendimia (ap. PÉREZ DE LA DEHESA, 1970: 29).

4 Para evitar incluir información innecesaria, aclaro que las citas de El señor feudal que a partir de ahora haga se corresponderán con $A, B$ y $C$, debidamente citados en la bibliografía. Por este motivo, cada vez que las mencione incluiré la letra en la referencia y, en el caso de $A$ y $B$, el número de la hoja y, en el caso de $C$, el número de la página. Asimismo, apuntalo que las citas reproducen fielmente los originales, conservando la particular fonética de los personajes y los errores gramaticales y ortográficos presentes en las tres redacciones.

5 Aspecto concienzudamente estudiado en Muñoz Álvarez (2018: 12-21), donde también se recogen las reseñas del estreno, las noticias sobre las siguientes representaciones y las ediciones publicadas. La última representación documentada tuvo lugar en Madrid, en el salón de actos del Instituto Municipal de Educación, el 21 de noviembre de 1963 («El señor feudal, de Joaquín Dicenta, en el Aula de Teatro», 1963: 82). He hallado el programa de la función, donde se indica que fue una lectura dramatizada dirigida por el actor y director Modesto Higueras. Se trataba de la cuarta sesión del ciclo «inquietud social», dirigido por el escritor Alfredo Marqueríe. En la sinopsis se expresa que «su mayor popularidad la alcanzó [Joaquín Dicenta] con Juan José, que no es, como durante mucho tiempo se pretendió, una pieza de inquietud social, ni mucho menos, una requisitoria política, sino simplemente un drama de celos de tipo realista trasladado, eso sí, a un ambiente y a unos personajes de humilde extracción. En cambio no cabe duda de que este autor fue en España un auténtico precursor de la angustia social llevada al teatro con la obra titulada El señor feudal». Para consultar el panfleto, acúdase al siguiente enlace: <https://cutt. ly/khc1Jg0> [Consulta: 1/9/2020]. 
torno al 3 de octubre, el autor ya habría concluido el primer acto de la obra y se encontraría rematando el segundo (ESE, 1896: 1). Unos pocos días más tarde, solo tenía que escribir las últimas escenas del drama («Noticias y sucesos», 1896: 2). El 17 de noviembre habría concluido la obra («Noticias de espectáculos», 1896: 3).

En este período tuvo que componerse $A$, el manuscrito autógrafo ${ }^{6}$. Tras un examen superficial, puede decirse que se encuentra en buen estado. Contiene numerosas tachaduras y enmiendas, está encuadernado en piel de color granate, y decorado con unas orlas amarillas en portada y contraportada y con motivos florales, también en amarillo, en el lomo. Tiene 133 hojas, escritas por el recto y el vuelto, aunque en ciertas partes solamente por el recto. Simón Palmer (1979: 61) indica que $A$ acabó en posesión de Juan de la Parra, del que no he obtenido información alguna; al menos acerca de ningún Juan de la Parra que guardara conexión con Dicenta. Una anotación en 1v firmada por una mano extraña a la del autor me ha hecho pensar que pudiera tratarse de un error de la catalogadora: la caligrafía es descuidada y a priori parece firmada por un hombre llamado así; sin embargo, una lectura minuciosa revela que el auténtico firmante es el escritor José Jurado de la Parra. Se desconocen las causas reales por las que se hizo con el manuscrito, pero bien pudiera deberse a la larga amistad que lo unía a Dicenta. No olvidemos que Jurado de la Parra le había dedicado su ensayo dramático Sinceridad y que posteriormente colaboró con él en la revista Germinal (CHIACHÍO PELÁEZ, 2009: 186), demostrando la existencia de un trato estrecho entre ambos escritores.

En la referida anotación, Jurado de la Parra cede su manuscrito a Narciso Díaz de Escovar («transmito este autógrafo, para su famosa colección, al ilustre escritor N. Díaz de Escovar»). Como no está fechada, no puedo precisar cuándo pasó a formar parte del archivo del bibliófilo malagueño. De lo que sí hay constancia es de que El señor feudal estuvo en poder de Díaz de Escovar al menos desde 1915, porque, hablando de su biblioteca, Solar y Taboada afirmó que «en la sección de Teatros, posee originales de escritores antiguos [...], que se mezclan con los borradores de las obras más aplaudidas del teatro contemporáneo, como [...] El señor feudal, de Dicenta» (1915: 19-20).

Tras la muerte de Díaz de Escovar, en mayo de 1935, su sobrino Joaquín María Díaz Serrano se convirtió en el heredero de su archivo, iniciándose «una etapa de dispersión del material, con la venta de muchos documentos» (GUTIÉRREZ, 2010). Uno de los textos vendidos pudiera ser $A$, que entonces pasó a formar parte de la colección de Arturo Sedó, como consta en la cédula de catalogación del manuscrito. Tampoco se menciona la fecha en que fue transmitido; debió ocurrir entre 1935 y 1954, momento en que la Caja de Ahorros Provincial de Málaga se quedó con los fondos conservados del archivo de Díaz de Escovar. En el año 1968, la Diputación de Barcelona adquirió todos los documentos de la colección de Arturo Sedó y los trasladó al Palau Güell. Actualmente, pertenecen al Centro de Documentación y Museo de las Artes Escénicas del Instituto del Teatro (CORTÉS, 2009: 13).

\footnotetext{
6 Así consta en la ficha catalográfica de la colección de Arturo Sedó. Vid. la dirección que a continuación enlazo: <http://www.cdmae.cat/sedo/imgtitulos/063/P0001023.gif> [Consulta 1/9/2020].
} 
$B$ también se encuentra en buen estado. Tiene 150 hojas escritas por recto y vuelto, y está encuadernado en piel de color negro con motas amarillas. La disparidad caligráfica evidencia que varias manos intervinieron en su redacción, además de las del propio Dicenta. En la página web de la Biblioteca Nacional, $B$ está fechado alrededor de 1896. Seguramente la copia se hiciera antes del día del estreno; es muy probable que durante octubre y/o noviembre, ya que a principios de octubre El señor feudal fue anunciado como una de las novedades de la cartelera del Teatro de la Comedia y a mediados de noviembre la compañía de Emilio Mario se encontraba inmersa en los ensayos del drama (MUÑOZ ÁLVAREZ, 2018: 13). Considero interesante resaltar que el manuscrito está sellado por la entidad teatral: el sello aparece en los rectos de las cinco primeras hojas de cada acto. Por todo ello, creo que $B$ habría de servir a alguno de los actores del estreno como libreto de trabajo para construir su personaje.

$C$ es un volumen en octavo, en consonancia con la tradición decimonónica, que había roto con la vieja costumbre de imprimir las obras dramáticas en cuarto (COTARELO Y MORI, 1928: 121-122). El libro tiene 79 páginas y su impresión se realizó en Regino Velasco, en Madrid. La edición corrió a cargo de la Administración Lírico-Dramática de Hijos de Eduardo Hidalgo ${ }^{7}$, cuyos comisionados fueron quienes se encargaron de conceder o negar el permiso de representación y el cobro de los derechos de propiedad. En la Gaceta de Madrid, de fecha 22 de enero de 1898, se publicó la relación de obras inscritas en el Registro general de la propiedad intelectual durante el primer trimestre del año 1897, y entre los títulos publicados figuraba El señor feudal, con el número 21466.

La princeps está fechada en 1896; tuvo que editarse inmediatamente después del estreno. Llegados a este punto, quiero subrayar el contraste entre la gran cantidad de información sobre las representaciones del drama y la ausencia de cobertura mediática de las ediciones, lo que dificulta reconstruir la transmisión del texto. No he hallado en la prensa ningún anuncio sobre la venta del libro, pero el 5 de diciembre ya podía adquirirse en las librerías: Martínez Ruiz relató un encuentro con Miguel de Unamuno en la librería Fernando Fe, acaecido tal día, en el que el bilbaíno cogió con desprecio un ejemplar del drama (ap. PÉREZ DE LA DEHESA, 1970: 28-29). Como en $C, 3$ se menciona el estreno en el Teatro de la Comedia, lo más plausible es sostener que la obra fuera distribuida entre los días 3 y 4 de diciembre.

Terminada la historia de la transmisión textual, analizaré las variantes más significativas de las tres versiones estudiadas y las posibles razones que las motivaron, basándome en el material extraído de la collatio codicum. Cuando compare fragmentos de $A, B$ y $C$, marcaré en cursiva los pasajes que han sufrido transmutaciones, sean adiciones u omisiones. Reproduzco también las tachaduras de los manuscritos, excepto en aquellos casos en que se extiendan largos períodos, en pro de la legibilidad.

7 El comercio de las obras teatrales estuvo monopolizado a lo largo del siglo XIX por una serie de entidades que en su mayoría fueron absorbidas por la Sociedad de Autores Dramáticos. En el caso de la que nos ocupa, la Administración Lírico-Dramática fue fundada en 1868 por Eduardo Hidalgo, quien la dirigió hasta su fallecimiento el 7 de marzo de 1896, momento en el que pasó a manos de su descendencia (COTARELO Y MORI, 1928: 131). 
De la confrontación de los tres textos puede deducirse que tanto la primera edición como $B$ proceden de $A$. No obstante, se aprecia un número considerable de cambios. La mayoría carece de valor; se trata de sustituciones léxicas que no alteran el sentido global de la obra: «trebaje» $(C, 12)$ por «trabaje» $(A, 8 \mathrm{r} ; B, 10 \mathrm{r})$ o «distraición» $(C, 50)$ por «distración» $(A, 69 \mathrm{v} ; B, 91 \mathrm{v})$. De esta forma el diálogo de los campesinos se empapa de coloquialismos en $C$.

Me parece interesante que algunas voces de $A$, sustituidas en $B$, se mantuvieran en $C$ : «arrematao» $(A, 54 \mathrm{v} ; C, 44)$ frente a «rematao» $(B, 78 \mathrm{v})$, «prencipales» $(A, 57 \mathrm{r} ; C, 46)$ frente a «principales» $(B, 81 \mathrm{v})$, «compaeciendo» $(A, 57 \mathrm{r} ; C, 46)$ frente a «compadeciendo» $(B, 82 \mathrm{r})$ o «dequivocarme» $(A, 59 \mathrm{r} ; C, 47)$ frente a «equivocarme» $(B, 84 \mathrm{r})$. Esto refuerza la idea de que $C$ se copió directamente del autógrafo.

Las abundantes correcciones de $B$ realizadas, probablemente, en el momento de la copia, tachones de los copistas que vendrían a subsanar de manera inmediata errores causados por descuidos, avalan la redacción de esta versión sobre el autógrafo. Así, una lectura apresurada de $A$ originaría confusiones y omisiones de palabras en $B$, verbigracia: «¿También a ti te parece mal lo que he dicho hecho?» $(47 \mathrm{v})$, «no lo estaba entonces tampoco entonces» (51v) o «que toda aquella tirantez riqueza tirantez de músculos» $(53 \mathrm{v}-54 \mathrm{r})$.

Con respecto a las variantes significativas, me gustaría comentar que un primer grupo atañen al texto extraliterario. Me resulta extraño que se hayan suprimido en $B$, el supuesto libreto de ensayo, casi todas las referencias didascálicas, puesto que estas habrían facilitado la mise-en-scène. Salvo el dramatis personae y la marcación de los actos y las escenas, junto con el nombre de los personajes que en ellas intervienen, no aparecen en $B$ las introducciones escénicas ni las acotaciones de $A$ y $C$. La ausencia del texto secundario podría explicarse acudiendo a la figura del director de escena, en este caso, Emilio Mario: tal vez él diera presencialmente a los actores las instrucciones concernientes a su comportamiento corporal, a la utilería y al decorado; puede que él sí trabajara con un libreto que contuviera las notas preliminares e interliminares; a lo mejor ese libreto fue $A$.

Por su parte, las referencias al paratexto en $A$ y $C$ presentan divergencias más o menos notables. La introducción escénica que abre el último acto es la que ha sufrido más cambios en $C$, y apenas tiene que ver con su original: 
El teatro representa la bodega de la casa de labor; puerta grande de una sola hoja e imitando madera claveteada al fondo; esta puerta que estará abierta al comienzo de la representación tendrá un gran cerro de hierro por la parte de adentro. El techo de la decoración será abovedado imitando piedra. Una rompiente a la derecha y otra a la izquierda; los bastidores y el fondo imitarán lienzos de pared en los que habrá empotrados barriles, cubas, etc.

También a la entrada de las rompientes y figurando continuar a lo largo de la galería se verán cubas y barriles.

En el centro de la escena pero a la izquierda para que pueda ser bien vista del público se verá la boca de una gran cuba que supone estar empotrada en el suelo. Esta boca será de madera ceñida por un aro de hierro, semejante en todo a la descrita en el acto primero; la boca de la cuba será practicable.

La escena entrará alumbrada, mitad por la luz del día que entra por la puerta de la bodega, mitad por un farol grande emprendido del techo en el centro de la escena. Esta El acto comienza a la caída de la tarde.

Al levantarse el telón aparece en escena Blas sentado encima de un barril vacío, fumando un cigarro, con un jarro de vino a los pies un pedazo de papel sobre las rodillas y un lápiz en la mano. El tío Juan junto a la rompiente de la derecha por la que saldrán llevando cada uno de ellos un cántaro de vino al hombro de Petra los trabajadores $1^{\circ}$ y $2^{\circ}$ dos trabajadoras; trabajadores $1^{\circ} \mathrm{y}$ $2^{\circ}$ y dos trabajadores más uno de los cuales será un niño de ocho a diez años.

Los trabajadores todos irán descalzos de pierna y usarán alpargatas de esparto $(A$, 98r-101r).
Bodega del señor Roque. Pipas de vino en varios sitios. En el centro dos barriles pequeños, en uno de los que está sentado Blas; en el otro hay un farol. Este segundo barril sirve de mesa a Blas, que, apoyado en él, saca una cuenta. En primer término derecha y casi de frente al público, se ve una puerta pequeña, $y$, abierta esta, permite ver la boca de la cuba descrita en el acto primero. La escena está alumbrada por el farol que tiene Blas y por otro que hay colgado de una viga $(C, 65)$.

La descripción de $A$ es mucho más prolija que en $C$ y además observamos la posición preeminente de la cuba, lugar de la tragedia. Dicenta consideraba este símbolo como un elemento clave de la acción; de hecho, era tal su importancia que lo empleó en otras dos obras íntimamente relacionadas con El señor feudal: el cuento «El desquite» (1893) y la novela Los bárbaros $(1912)^{8}$. En las tres composiciones, la cuba de la bodega representa la explo-

8 Fernández Insuela (2003: 2017) se percató de esta práctica habitual en el autor bilbilitano: «varios de sus escritos escénicos son la versión teatral de un cuento editado previamente o de una novela publicada poco des- 
tación del campesinado. Del mismo modo que el vino eucarístico se transubstancia en la sangre de Cristo, la cuba es el recipiente donde la sangre de los labradores se convierte en el vino que ha de engrosar la riqueza del terrateniente. Así, en testimonio de Jaime:

Y cuando fui mayor, cuando empecé a comprender lo horrible de nuestra condición, cuando en la época del pise de la uva y el trasiego de vino, veía a mi padre, a mi abuelo, a los hermanos de mi padre, a mí mismo, hombres, mujeres, niños, todos ennegrecidos por el sol, untados de mosto, sudosos, jadeantes, con la espalda encorvada, los músculos contraídos, temblorosas las piernas y la cántara de vino sobre los lomos, llegar a aquella cuba enorme y vaciar en ella las cántaras y volver con otras y vaciarlas otra vez, sin que la cuba dijese nunca '¡basta!' siempre insaciable, con la boca abierta, como si no tuviese fondo, entonces encontraba monstruoso, inicuo, que todo aquel trabajo, que toda aquella tirantez de músculos y aquel sudor de hombres fuesen para uno solo, y aumentaba mi odio y sentía una angustia infinita, mezclada con un aborrecimiento salvaje, y me parecía que el líquido que humeaba y burbujeaba en aquel abismo artificial, líquido de color de sangre, era la sangre de todos los míos esprimida allí, estrujada allí sin compasión, en provecho de una raza entera de propietarios. $(C, 31)$

Muchos estudiosos han notado que, tradicionalmente, el vino, en especial el vino rojo, ha simbolizado la sangre y el sacrificio (CHEVALIER Y GHEERBRANT, 1986: 1072; CIRLOT, 1987: 464). En este caso, el término sacrificio no debe entenderse como una «ofrenda a una deidad en señal de homenaje o expiación», sino como «peligro o trabajo graves a que se somete una persona» ${ }^{9}$. La cuba, además, se halla en el suelo, como si fuera un sepulcro o una abertura que comunica con el infierno.

Quizás otro aspecto destacable sea la traslación a la izquierda de numerosas entradas y salidas de los personajes que originariamente sucedían por el «fondo». Son variantes del tipo «entran por el fondo el tío Juan y los trabajadores $1^{\circ}$ y $2^{\circ}$ » $(A, 48 \mathrm{v})$ por «entran por la primera puerta izquierda el tío juan y los Trabajadores $1 .^{\circ}$ y $2 .^{\circ} »(C, 39)$, «Petra ayuda a Blas a coger el serón y sale con él por la puerta del fondo» $(A, 64 \mathrm{r})$ por «cogen entre los dos el serón y vánse con él por la primera izquierda» $(C, 48)$, o «se dirige al fondo por donde entra Blas» $(A, 141 \mathrm{r})$ por «se dirige hacia la primera izquierda por donde entra Blas» $(C$, 73). Tan solo he encontrado en la edición impresa una única excepción a esto, tal vez un error: al final de la segunda escena del segundo acto se dice que «entra Blas por el fondo, donde se detiene» $(C, 43)$.

Cabría conjeturar que la arquitectura del Teatro de la Comedia no permitiese entrar y salir por el fondo. Sancha Fernández (2015: 1639-1682) ha recogido la memoria y la documentación gráfica del expediente de licencia de obras de dicho inmueble, localizado en los archivos de la Villa de Madrid. En los planos originales de 1874, al fondo del escenario del coliseo existía una comunicación — de pequeñas dimensiones, tal vez una puerta- con la Casa n. ${ }^{\circ} 9$ de la calle de la Gorguera. En la memoria se indica que dicha casa se añadiría para el servicio del teatro, pero no se cita la fecha exacta en que se adquirió el inmueble. Su

\footnotetext{
pués». Para una visión más precisa acerca de la relación genética entre «El desquite», El señor feudal y Los bárbaros, vid. Muñoz Álvarez (2020: 141-162).

9 Definiciones tomadas del Diccionario de la lengua española.
} 
propietario, Silverio López Larrainza, solicitó al ayuntamiento de Madrid el 24 de febrero de 1873 la licencia para el derribo, valla y construcción de la referida casa (SANCHA FERNÁNDEZ, 2015: 1677). En los planos de 1874, de Agustín Ortiz de Villajos, ya aparece una comunicación del escenario con la vivienda, por lo que lo más lógico es suponer que en 1874 ya se tuvieran derechos sobre ella (SANCHA FERNÁNDEZ, 2015: 1662-1669).

Por otra parte, la memoria tampoco revela la auténtica función de la casa. El habitáculo bien pudiera haber servido para la entrada y salida de los actores, bien para otro fin. De hecho, en el plano de la planta baja (SANCHA FERNÁNDEZ, 2015: 1664) había en los laterales del escenario unas dependencias — un patio cubierto y una escalera, a la izquierda; otro patio cubierto y un cuarto, a la derecha- que podrían haber sido utilizadas por el reparto para salir a escena. Los accesos de estos espacios eran mucho más amplios y cómodos que el del fondo. Otra posible explicación, mucho más sencilla, sería la adecuación de las entradas y salidas de los personajes a la distribución del decorado.

Asimismo, en $A$ hay unas pocas acotaciones sonoras o auditivas que no han sobrevivido en $C$, como, por ejemplo, Petra «cantando con aire de jota» una cancioncilla ${ }^{10} \mathrm{o}$ «golpeando al caballo con un látigo» $(A, 3 r)$. Por lo general, el esfuerzo descriptivo es mayor en el manuscrito autógrafo que en la edición impresa. Puede que, al no poseer las referencias concretas del lugar de la representación, Dicenta fuera deliberadamente explícito en este aspecto.

Otro conjunto de variantes lo forman aquellas intervenciones en ambos manuscritos que fueron eliminadas en $C$ con el objeto de atenuar el melodramatismo de ciertos momentos redundantes, que nada aportaban ni a la trama social ni a la sentimental. Su arraigo con los temas recurrentes del teatro aurisecular — honor, celos y venganza-, que tanto satisfacían al público mayoritario, vendría a explicar el carácter efectista del drama social. Este pasaje tachado en $A$ y, por consiguiente, omitido en las demás versiones del drama se recreaba en el infortunio económico y familiar del Marqués de Atienza, cuyo patrimonio había pasado a manos del señor Roque junto con su suerte. Este personaje, dirigiéndose a María, nieta del noble, le decía:

Crea usté que sin mí hubiera llegao enantes la ruina. He sacao de muchos apuros a su padre de usté. Su mismo abuelo tendría sus bienes en poder de la curia si yo no le hubiera dao lo preciso... (deteniendo un gesto de María) con un interés claro, que el dinero es pa rentar lo suyo; pero el caso es que salió del aprieto $(A, 75 \mathrm{v})$.

10 «Deja tú que el sol te tueste / y que te ponga moreno; / tuesta al trigo el sol y el trigo / cuanto más tostao más güeno» $(A, 3 r)$. Este canto contribuye a localizar en la geografía la aldea innominada en la que sucede la acción del drama. Algunos críticos han señalado que se trata del campo andaluz (MAS FERRER, 1978: 138; MCGRATH, 2004: 111-112). Sin embargo, Muñoz Álvarez (2020: 143-144) concluía que eran insuficientes las razones intrínsecas que pudieran sustentar tal postura. En cambio, su parentesco con Los bárbaros sí que podría justificar la localización en Andalucía: Dicenta ubicó el pueblo ficticio de la novela, Mérina o Merina, en dicha comunidad. Con la luz arrojada por $A$, manteniendo la hipótesis de la aldea andaluza, la acción podría circunscribirse a la Alta Andalucía; si bien es sabido que la jota ha arraigado en buena parte de nuestro país. Cualquier afirmación tajante a este respecto es muy arriesgada, en virtud de la debilidad de las pruebas con que se opera. La modalidad lingüística de los personajes tampoco es concluyente; en los dramas rurales la forma de hablar de los personajes solo demuestra su adscripción a un nivel sociocultural bajo (PACO DE MOYA, 1971-1972: 143). 
Una extensa conversación mantenida por Jaime y María en $A$, totalmente tachada, dejaba entrever en esta primera versión el afecto del maquinista por la marquesa, una trama amorosa secundaria que, en mi opinión, solo servía para desviar al lector/espectador del conflicto primordial. Por la redacción caótica y entrecortada, y por una indicación escrita en el margen («ojo»), se hace evidente que Dicenta no habría terminado el diálogo. A continuación, reproduzco la parte que me interesa:

Jaime.- Es natural que usté lo niegue; la repugnancia que le inspira esa boda, porque en negarlo estaba que en que nadie lo sepa estriba que su sacrificio de usté no resulte inútil porque si no lo negase sería buena a medias y los ángeles son buenos del todo

Juana $^{11}$.- Jaime...

Jaime.-Si es natural que usté lo niegue que con su conducta haga creer a todos y al señor marqués el primero que quiere a Don Carlos, pero yo... yo que sé hasta qué punto es altivo su corazón de usté hasta qué punto son delicados sus sentimientos sé que usté no puede quererle, que no le querrá nunca.

María.-Y tú por qué me hablas de ese modo! ¿Quién te ha dado derecho por tanto. Quiero a Carlos, ¿lo entiendes?... Por qué no he de quererle yo?

Jaime.-_Por qué? Porque no es posible; porque es mozo vanidoso, vulgar, hijo de un criado de su padre de usté, no ha podido inspirarle a usté más que indiferencia o desprecio.

María._Basta Jaime...!

Jaime.-Nada más que eso ha podido inspirarle a usté. Cómo voy yo a creer lo contrario, cómo voy a pensar, a sospechar siquiera otra cosa... Yo valgo más que él por mi entendimiento y mi corazón, ya que no por mi cuna valgo más que él y si alguna vez hubiera cruzado por mi cerebro la idea de ser querido por usté, la hubiese visto a usted tan alta, me hubiera visto yo tan bajo, que hubiera rechazado semejante idea como una locura. ¿Cómo he de creer yo conociéndola a usted, que él iba a ser digno de lo que yo no me hubiera atrevido a soñar siquiera.

María._Jaime...

Jaime.- - No, no crea usted en mis palabras la manifestación de afectos egoístas, el eco de pasiones que no existen en mí; es la comparación, es la lástima, es la verdad lo que me obliga a hablarle y la verdad es que usted se sacrifica por su abuelo $(A, 129 r-131 r)$.

Al no incluirse en $B$ ni en $C$, los sentimientos de Jaime se hicieron menos evidentes. Una charla con Juana constituiría la única prueba de ello. En la escena XII del primer acto, la campesina insinuó que antes su hermano miraba a María «mu fijo, como se mira, como se debe mirar cuando se quiere mucho; como embelesao, como enamoricao, ¡vamos!». A lo que él respondió que solo la quería «como a una amiga», ese es el único modo en que podía quererla «mientras no cambie el mundo» $(C, 32)$. Tras estas palabras subyace una idea, la distancia insalvable que separaba a las clases sociales; así lo declaraba Jaime de nuevo en otro parlamento tachado en $A$, invalidando la posibilidad planteada por Torrente Ballester (1957:64) de un matrimonio morganático entre Jaime y María, de haber tenido la obra un desenlace feliz:

11 El autor menciona equivocadamente a Juana. 
¡Qué estás hablando!... No has oído que María la señorita María tiene en mueho et orgullo o las preoeupaeiones de la elase-a que perteneee para enamorarse del hijo de un eriado suyo? No sabes que él como yo, eomo etalqutiera de nosotros, ni siquiera es para ella un hombre. desprecia a Carlos; no lo ha oído Petra de su boca. ¿Por qué te empeñas en negar esto? ¿Qué obstinación es esa tuya? ¿Qué quieres decir? (A, 60r-61r).
¿Qué estás hablando?... ¿No has oído que la señorita María desprecia a Carlos? ¿No se lo has oído a Petra? ¿Por qué te empeñas en negar esto? ¿Qué obstinación es esa tuya? ¿Qué quieres decir? ( $C, 47 ; B, 85 \mathrm{r}-85 \mathrm{v})$.

En $A$ y $B$ encontramos también una breve afirmación de este personaje sobre el papel que desempeñan las mujeres y los hombres en el desquite: «las mujeres a pedir reparación de sus ultrajes; los hombres a dársela tú la voz que reclama justicia yo el brazo que hiere; cada uno a lo suyo» $(A, 140 \mathrm{r})$. Como Juana ha mancillado la honra familiar al dejarse seducir por Carlos, a Jaime no le queda más remedio que urdir y ejecutar la venganza. Forgas Berdet (1983: 46) advierte que «solo la mujer es la culpable del deshonor masculino y es por ello que Dicenta lanza contra esta sus iras». En este caso, por el contrario, Jaime absuelve a su hermana de toda culpa, alegando su credulidad característica: «Te absuelve tu ignorancia, como le condena a él su engaño!» $(C, 62)$.

Otro comentario machista, suprimido en $C$ y presente en $A$ y $B$, lo pronuncia Blas. Hablando con Jaime sobre las causas por las que María ha aceptado desposarse con el señorito, alude al carácter interesado de la joven aristócrata, condición que considera inherente al género femenino: «iBah!... Ya sabes lo que son las mujeres! Aluego, tamién hay que ver que Don Carlos tié muncho dinero que la llevará a Madriz a que se luzca. Y entre ser una personaja en Madriz y una señora troná en la aldea habrá escogío lo mejor» $(A, 112 r-113 r$; $B, 124 \mathrm{v})$.

En boca de Blas, Dicenta efectúa en $A$ y $B$ una crítica a la institución del matrimonio, tema recurrente en su producción (MCGRATH, 2004: 237-238). Esta apreciación desaparece en $C$, tal vez por su contenido digresivo: 
Los novios son novios; y como se quieren se buscan y como se buscan se encuentran $\mathrm{y}$ andan por ande puen, por los caminos y por los sembraos, a la sombra e los árboles cuando hace sol y a la e las nubes cuando hace luna y solos se entienden que como los trigos son altos y los árboles son espesos naide pue saber lo que hablan. Solo que esto no va pa mal, porque un día se enteran los padres y cogen a los chicos y les icen to erecho y el siñor cura les echa beniciones y casaos pa siempre y en paz; juera parte de los regaños y de las hambres y de las palizas y de lo que sucea dempués de casaos, que la soga el matrimonio es larga y icualquiera averigua los enreijos que llegará a tener con el tiempo!... $(A, 10 \mathrm{v} ; B, 13 \mathrm{r}-14 \mathrm{r})$.
Los novios son novios; y como se quieren, se buscan, y como se buscan, se encuentran, y andan por ande pueen, por los caminos y por los sembraos, a la sombra de los árboles cuando hace sol, y a la e las nubes cuando hace luna, y solos se entienden, que como los trigos son altos y los árboles son espesos, naide pue saber lo que hablan. Solo que esto no va pa malo, porque un día se enteran los padres y cogen a los chicos y les icen: too derecho, y el señor cura les echa las beniciones y casaos pa siembre, y en paz (C, 13-14).

No obstante, los cambios más notables de este conjunto de variantes afectan a la caracterización de los dos antagonistas: el señor Roque y su hijo Carlos. Ambos pertenecen a una clase social denostada por el autor: la burguesía ${ }^{12}$. Es evidente la construcción maniqueísta de estos personajes. Dicenta decidió prescindir en $C$ de determinados fragmentos que incidían en el carácter negativo de estos personajes, fragmentos que en nada servían a su desarrollo psicológico. Así, para evitar caer en redundancias, eliminó en $C$ unas palabras de Jaime, presentes en $A$ y $B$, que insistían en la carencia de escrúpulos de Roque:

La señorita María, el señor marqués, todos los que vivís en este pedazo de tierra dominada por el señor Roque estáis a merced suya. Nada podéis tener eontra su voluntad porque de su voluntad depende vuestro porvenir y os tiene en su poder eogidos, no es vuestra existeneia... Es el amo, él por eletrello [ilegible]... Os tiene cogidos no por el cuello, por el estómago. El día en que os neguéis a una orden a un capricho suyo, no os acogotará, os matará de hambre y el hambre es un consejero muy cobarde y muy egoísta. Grita yo, yo, yo primero que nada y ante ese grito cede todo el orgullo, la dignidad, la energía, la honra, se achican, desaparecen, sucumben. Qué haríais vosotros si ese hombre lo determinara, si se eoloeara entre la miseria y la humillaeión y el saerifieio? ¿qué harrais etuanto el hombre os retoreiera eomo tha tenaza de hierro eles= tómago? ¿qué harrais sino eaer de rodillas a los pies del señor Roque, de ese viejo ruin y miserable que se ríe de todos vosotros mientras amontona talegas y tategas de oro en los rineones de strs areas. (A Juana) Tú misma, mi hermana, el único ser a quien he querido y quiero de veras, eres esclava suya. Pobre Juana, ¿qué sería de ti si él quisiere!... (Con energía) No; de ti no, que yo estoy contigo y soy libre y tú y mi padre podéis reíros del señor Roque mientras estos brazos hagan crujir el hierro entre los dientes de una máquina. $(A, 61 \mathrm{r}-63 \mathrm{r} ; B, 85 \mathrm{v}-86 \mathrm{v})$

12 Llama la atención que la imagen que Dicenta ofreció de la aristocracia en El señor feudal no fuera negativa; al contrario, estuvo marcada por el respeto, la simpatía y la conmiseración. En un intento por esclarecer tal circunstancia, la crítica ha aducido varias explicaciones como las raíces nobiliarias del autor (MAS FERRER, 1978: 146) o su carácter tradicionalista (TORRENTE BALLESTER, 1957: 63). 
Las palabras de Torrente Ballester no pueden ser más acertadas: los personajes del drama se estructuran en una pirámide, «cuya cúspide ocupa el pobre marqués de Atienza, y a cuyos lados se agrupan, en correlación, el Tío Roque y el Tío Juan; Jaime, hijo de Juan, y Carlos, hijo de Roque; Juana, hermana de Jaime, y María, la marquesita» (1957: 126). El poder de Roque reside en su riqueza, gracias a la cual determina la suerte de sus trabajadores. Una réplica de Roque a su hijo, elidida en $C$, hacía hincapié en este aspecto: «¿Crees que cuando yo apetezco algo dejo a lo que me lo han de dar en situación de decir 'sí o no'? El día que yo doy la cara en cualquier negocio no hay más remedio que decir 'sí'. Mientras tanto no enseño las cartas. Ahora voy a tirarlas encima de la mesa. Calcula si estaré seguro de ganar $(A, 16 \mathrm{v}-17 \mathrm{r} ; B, 22 \mathrm{v}-23 \mathrm{r})$.

Con respecto a Carlos, este actúa como un donjuán: embaucador de Juana, va a desposarse con la marquesa por conveniencia. Su asesinato en la cuba no es más que la lógica consecuencia de la justicia poética por su conducta reprobable. Al igual que ocurrió con su padre, en $C$ también se han suprimido fragmentos innecesarios que reiteraban su egoísmo. Sirva de ejemplo una intervención de Jaime en $A$ y $B$, acortada en $C$, donde se referían las malas prácticas del señorito:

Sí eso es, eso. La mentira, la falsedad, el acecho perpetuo de la honra para caer sobre ella a mansalva!... Tarea fácil para un señorito hecho a saltar de engaño en engaño por las callejas de la corte sorprender a una criatura mujer, a una niña casi, hecha a saltar sin otro guía que su instinto por los peñascos de la montaña! Tarea fácil, para ese miserable seducirte con sus palabras dulces, con sus juramentos de amor, con la elegancia de su traje, con el atractivo de sus maneras...! Tarea cobarde seguida sin descanso, sin tregua, con la perseverancia de un apetito que desea satisfacerse...

Y esto un día y otro a todas horas; y tú inocente, sin defensa, sin consejero, sola con él; y él al lado tuyo mintiendo y mintiendo más, siempre más, cegándote con sus mentiras, aturdiéndote con sus halagos... hasta que una noche cualquiera abrió los brazos y caíste en ellos sin saber siquiera que caías!... (con rencor profundo) ¿Qué canalla! (A, 91r-92r; $B, 112 \mathrm{v}-113 \mathrm{v})$.
¡Sí, eso es, eso! Tarea fácil para ese señorito, sorprender a una mujer, a una niña casi. Tarea cobarde, seguida sin descanso, sin tregua, con la perseverancia de un apetito que desea satisfacerse... Y esto un día y otro, a todas horas, y tú inocente, sin consejero, sin sostén, sin apoyo, sola con él; y él al lado tuyo mintiendo y mintiendo más, siempre más, hasta que una noche cualquiera abrió los brazos y caíste en ellos sin saber siquiera que caías... ¡Qué canalla! (Con rencor.) $(C, 61)$.

Caso muy distinto constituye la siguiente serie, compuesta por unas pocas variantes encaminadas a rebajar el contenido social del drama; en su mayoría vuelven a ser omisiones en $C$ de fragmentos que estaban en $A$ y $B$. Está claro que Joaquín Dicenta no fue Gerhart 
Hauptmann ${ }^{13}$; como muchos otros autores progresistas del momento, su ideología «respondía más a motivaciones emocionales o sentimentales que a una meditada elaboración teórica» (FERNÁNDEZ INSUELA, 1998: 30). Con todo, estuvo muy comprometido con el tiempo que le tocó vivir. De hecho, él mismo declaró que la misión del escritor consistía en «recoger de la realidad palpitante aquellos problemas sombríos, que agitan y corroen a las modernas sociedades, y presentarlos a los ojos del público solicitando, con el poderoso lenguaje del arte, su resolución y su remedio» (ap. MAS FERRER, 1978: 63). Por medio de sus escritos - tanto periodísticos como literarios- denunció la precariedad de la clase obrera, e incluso llegó a posicionarse del lado del lumpemproletariado. Por ejemplo, desde sus inicios literarios Dicenta abordó con actitud crítica un problema de gran calado en la sociedad española del período finisecular, la prostitución, «equiparando el burdel a la problemática de la mina, el campo o la fábrica» (JIMÉNEZ MORALES, 2020: 113).

La reducción del contenido crítico de El señor feudal en $C$ no fue un intento de eludir la censura administrativa, pues esta llevaba sin operar en el país desde $1881^{14}$. Además, ninguno de los pasajes eliminados podría considerarse lo suficientemente radical. Ahora bien, es cierto que el drama fue prohibido, por un motivo que ignoramos, por el alcalde de Palma (DICENTA, 1897: 1). Me inclino a pensar que todas estas omisiones se debieron, como en el caso anterior, a un intento por prescindir de todo el contenido que fuera pleonástico y pudiera suponer un paréntesis en el conflicto principal. Ni siquiera cuando Jaime denunciaba en $A$ y $B$ el trabajo infantil lo hacía de un modo directo: «mira aquel niño.

13 López Criado señaló que «mientras Hauptmann colectiviza la lucha de clases [...], Dicenta la personaliza o individualiza [...]; mientras los dramas de Hauptmann remiten a un pensamiento revolucionario (de claro sesgo marxista), los dramas de Dicenta nos arrastran hacia un sentimiento revolucionario; y como principal rasgo diferencial, mientras el teatro de Hauptmann orienta su revolución (social y teatral) hacia un público proletariado, Dicenta se dirige a un público principalmente burgués» (2011: 1199). Dicenta nunca perteneció a la Generación del 98 y en sus escritos osciló entre el antitradicionalismo y el tradicionalismo (HALL, 1952: 66).

14 Desde el punto de vista jurídico, la situación de la censura en 1896, en nuestro país, era imprecisa por la sucesión de normas que contravenían la Constitución de 1876, entonces en vigor. El Reglamento de Policía de Espectáculos del 2 de agosto de1886, aplicable hasta 1913, citaba la vigencia del Reglamento de Teatros de 28 de julio de 1852, que en el art. 38 de su capítulo sexto expresaba que «cuando haya de someterse a la censura una producción cualquiera se remitirán dos ejemplares de ella al expresado Gobernador, y este los pasará al censor». El Reglamento de Policía de Espectáculos señalaba también en su parte expositiva que, pese a la vigencia del Reglamento de Teatros, muchos de sus preceptos resultaban «deficientes, y mucho más después de abolida la previa censura para todas las manifestaciones del pensamiento». Lo cierto es que la Constitución de 1876, en su art. 13, determinaba que la ciudadanía podía «emitir libremente sus ideas y opiniones, ya de palabra, ya por escrito, valiéndose de la imprenta o de otro procedimiento semejante, sin sujeción a la censura previa». A pesar de este mandato constitucional, la Real Orden de 27 de febrero de1879 impuso a los gobernadores civiles la obligación de remitir al Ministerio de la Gobernación, diez días antes del estreno, dos ejemplares de cada obra dramática, para precaver ataques a la moral. Dado que esta disposición era contraria al indicado art. 13, fue derogada por la Real Orden de 26 de febrero de 1881, porque se entendía que para prevenir esos ataques, en caso de que fueran constitutivos de delitos, ya estaría la jurisdicción competente. En consecuencia, tomaba dos medidas: para las obras que iban a representarse, los empresarios habían de poner en conocimiento de la autoridad gubernativa superior el título de la obra y el nombre del autor; para los dramas que iban a imprimirse, se remitía a la Ley de Imprenta de 7 de enero de 1879. De acuerdo con lo expuesto, la censura previa finalizó en 1881. Por tanto, la prohibición de subir a las tablas El señor feudal en el Teatro Principal de Mahón, por parte de su alcalde, no tenía cobertura legal, de ahí la queja de Dicenta en una carta publicada en varios diarios (DICENTA, 1897: 1). 
Apenas sí tiene diez años y ya va con la carga encima. Las caballerías tienen más suerte. A los potros no se les carga se les deja trincar libres y sueltos por la dehesa» $(A, 117 \mathrm{r} ; B$, $125 \mathrm{v})$. El autor no animaliza al Niño, no lo compara con los potros porque estos corren mejor suerte que él; en cambio, lo degrada, lo sitúa por debajo del ganado. El amo de las tierras priva de derechos y libertades a sus trabajadores, no importa cuál sea su edad. La escena que Jaime describe recuerda a otra de Los bárbaros en la que se nos presenta a Perico, de diez años, que, de tanto trabajar, se desmaya «entre las espigas, inmóvil, con los puños cerrados, la faz roja, los ojos en blanco, la boca entreabierta y las venas del cuello negras, abultadas, tirantes» (DICENTA, 1912: 53) $)^{15}$.

Una brevísima exclamación de Blas en $A$, omitida tanto en $B$ como en $C$, incidía en el ánimo del campesino, en lo cansado que se encontraba y en la necesidad de disponer de tiempo para descansar y recuperarse. Dicenta ahonda, pues, en las duras condiciones en que los trabajadores del campo realizan sus faenas: «iQué ganas tengo de de vivir de parar una hora de parar una hora escansao» $(A, 69 \mathrm{v})$.

En el manuscrito autógrafo encontramos también algunas intervenciones de Jaime que refieren la dureza del trabajo agrícola. En 35r, está tachado un comentario en el que comparaba la tierra con una «esponja insaciable que se traga la sustancia y la inteligencia del trabajador». Por supuesto, ha sido eliminada en $B$ y en la versión impresa. Otra de sus intervenciones en $A$ ha sufrido modificaciones en $B$ y $C$. En ella, Jaime denunciaba las abusivas jornadas laborales de los campesinos incidiendo en los efectos perniciosos que sobre su salud tenían las condiciones climatológicas adversas con las que a menudo lidiaban:

¡Trabajar sin tregua, a todas horas, en verano, en invierno, a campo abierto, con el sol que tuesta la piel, con el frío que agrieta la carne, con la lluvia que azota la cara, con la nieve que entumece el cuerpo!... Y esto un día y otro y ¿para quién!... ¿para él? $(A, 33 \mathrm{v})$.
¡Trabajando sin tregua, a todas horas, en verano, en invierno, a campo abierto, con el sol, con el frío, con la lluvia, con la nieve! Y esto un día y otro, y ¿para quién? ¿para él? ( $C, 29 ; B, 49 \mathrm{r}-49 \mathrm{v})$.

Un último conjunto de variantes lo integran unos pocos comentarios de $A$ y $B$ que, de haber sobrevivido en la editio princeps, hubieran modificado el argumento de la versión del drama que hoy conocemos. Por ejemplo, la cantidad de dinero a deber del Marqués habría sido considerablemente inferior de haberse mantenido lo dicho en los dos manuscritos: cinco mil duros, en lugar de diez mil. En esta ocasión, Dicenta prefirió agravar la ruina del

15 El dramaturgo siempre estuvo preocupado por la situación de los niños. Para él, la infancia constituía el «símbolo de que el mundo podía ser más igualitario y ejemplo de cómo la sociedad destruye la armonía humana y natural» (TRUJILLO, 2015: 143). Creía que la semilla del cambio social se encontraba en los más jóvenes, de ahí sus intentos por mejorar el sistema educativo español, materializados en su Informe sobre reorganización de la enseñanza municipal de Madrid (1910), donde aseveró tajantemente que procurar una buena educación durante la niñez constituye un interés de bien común. «Ningún deber más noble para este Municipio que el de convertir sus escuelas de niños en semillero de hombres cultos y de ciudadanos viriles», ya que «en la infancia, se dice, está en germen, todo el porvenir nacional» (DICENTA, 1910: 4, 5). Para Dicenta, el lugar del niño se encontraba en la escuela y no en la fábrica trabajando, ni en el campo segando, ni en la mina cavando. 
aristócrata. Asimismo, $C$ comportó cambios temporales respecto de $A$ y $B$. La duración de la partida de Carlos se amplió en primera edición: de los once días de los manuscritos, a los quince de la impresión de R. Velasco. Esta transformación acrecentaría la incertidumbre de todos los personajes, en concreto de María y Juana.

Por otra parte, en $C$ faltaban veinte días para el vencimiento del pacto de retroventa; en cambio, en el caso de $A$ y $B$ este hubiera vencido en tan solo siete. Se subsana así un error de los manuscritos, pues los días que el señorito está fuera del pueblo habrían excedido el plazo que el aristócrata tenía para pagar la deuda contraída con Roque. En ese lapso debería oficiarse la boda entre Carlos y María. En realidad, a pesar de que no se concreta la fecha de las nupcias en ninguna de las tres versiones, puede deducirse que la ceremonia tendría lugar en un período igual o inferior al referido plazo, porque, de lo contrario, Roque perdonaría en balde la deuda al Marqués, ya que su nieta podría anular el enlace en cualquier momento, según su voluntad. De hecho, como ella misma declara, Carlos no despertaba en ella ningún tipo de atracción, ni siquiera afecto: «¿De qué te serviría que yo me uniese a tu hijo, si ni mi alma ni mi pensamiento, ni nada de lo que vale en mí le iba a pertenecer?» $(C, 56)$.

En $A$ el número de personajes que participan en la trama es mayor. Aunque no es mencionada en el dramatis personae y tampoco tiene diálogo, la criada de María sale a escena en el segundo acto. En $B$ y $C$ el autor prescindió de su papel, si bien se alude a ella en una acotación a un parlamento de María: «Buenas tardes. Espérame ahí fuera. (Como dirigiéndose a una criada que la acompaña y que no aparece» $(C, 51)$. Se trata de un personaje episódico que no aporta nada al conjunto de la obra, por lo que su ausencia en la versión final estaría más que justificada.

Por último, me detendré en el desenlace del drama, el momento en que los dos ejes temáticos que hasta entonces habían corrido paralelos —el conflicto social y el amorosose imbrican para provocar el clímax: el asesinato de Carlos en la cuba a manos de Jaime. López Criado argumenta que nuestro dramaturgo sabía muy bien que «la burguesía progresista» no se implicaría en la revolución que planteaba si el obrero aparecía «como protagonista de la lucha armada»; por eso, «antes que elevar sus personajes a la categoría de héroes, Dicenta prefiere presentarlos como víctimas» (2011: 1202). En este sentido, en El señor feudal la muerte del señorito suponía la reparación de Juana y el fin de la tiranía del señor Roque al truncarse sus anhelos de emparentar con la nobleza mediante un nieto. Concluye $C$ con esta intervención de Jaime: «¿Creías que el amo eras tú? ¡No; el amo es Dios, y te castiga en lo que más amabas: en tu hijo! A ver si con todo tu poder puedes salvarlo. ¡Anda, sálvalo! ¡Sálvalo, si puedes! (Arrojándole la llave a los pies)» $(C, 79)$.

Dicenta pensó y repensó bastante el final de su drama, como demuestran los tres posibles desenlaces que ensayó en $A$. No le convencería en absoluto el primero de ellos, el más escueto de todos, porque acabó tachándolo por entero: «Tu hijo, sí tu hijo. Ahí está. Yo lo he matado. Prueba a ver si con todo tu poder y con todo tu oro lo puedes salvar. Anda, prueba, sálvalo si puedes» $(A, 158 \mathrm{r})$.

La segunda alternativa es más melodramática, incidía en todo lo que el señor Roque estaba perdiendo dentro de la cuba: «Tu hijo... sí. El deshonrador de mi hermana, el instrumento de tus ambiciones, el heredero de tu oro caudal, tu esperanza, tu porvenir... No dices 
que puedes tanto... Ahí está. A ver si con todo tu oro puedes salvarlo de ahí... Anda, sálvalo, prueba, sálvalo!...» (159r).

La tercera opción barajada es la más próxima a la que ha llegado hasta nuestros días y en ella el maquinista apela a Dios como valedor de sus actos:

Salvarle... No podrán. No ves que está ahí dentro que tengo yo la llave y que no es tan fácil quitármela!... ¡Salvarle!... Pero qué te creías que tú eras el amo. No el amo es Dios. Dios te castiga en tu hijo. Ahí lo tienes a ver si con todo tu poder lo puedes salvar. Anda, sálvalo, sálvalo si puedes. (159r).

La versión de $B$ tampoco es idéntica a esta última, pero son mayores las concomitancias con $C$ : «No puedes, no ves que no puedes. Creías que eras el amo, no: el amo es Dios! No creías poderlo todo. Anda señor Roque, sálvalo, sálvalo si puedes» $(B, 150 \mathrm{v})$. Me sorprende que Dicenta acabara decantándose por la invocación a Dios. Cuesta entender esta decisión, sobre todo si tenemos en cuenta una conversación que mantuvo con su médico poco antes de fallecer, recogida por González Blanco, su biógrafo: «Cónstele a usted que ha llegado mi fin y que muero fuera de toda confesión religiosa, manteniendo mis ideales y mirando cara a cara a la muerte, ya que me he jugado la vida con energía y rapidez» (1917: 278). McGrath ha subrayado que «although Dicenta is far from anticlerical, he does not adhere to any particular creed» y que «in those plays where the clergy plays a part, Dicenta uses religion to represent the conservative attitude, yet the majority of the time Dicenta invests the order with dignity, sincerity, and intelligence» (2004: 237). Sin embargo, se sabe que el bilbilitano participó en Don Quijote, «uno de los semanarios políticos más anticlericales del siglo XIX» (GUTIÉRREZ CARBAJO, 2003: 740), y la visión del estamento religioso en «El desquite» y en Los bárbaros no es para nada positiva: en ellas los clérigos se valían de su influencia para alienar a la clase trabajadora (MUÑOZ ÁLVAREZ, 2020: 156157). No parece, por tanto, que Dicenta simpatizara con la institución eclesiástica, en particular, ni con el cristianismo, en general.

Martínez Ruiz mostró abiertamente su disconformidad ante este final a través de estas palabras publicadas en El País: «¿Hablar de Dios, del cielo, de la sangre noble, que no puede ser robada por los administradores? ¿Qué inmensa distancia entre eso y los arranques de Juan José!» (ap. MAS FERRER, 1978: 149). Es posible que la alusión a Dios sea una herencia del teatro nacional: en las obras áureas, el rey poseía «un destello de divinidad, pues de Dios recibe su realeza» y «solo Dios puede castigarle» (RUIZ RAMÓN, 2011: 137). En sus «dramas del poder injusto», Lope de Vega hacía acudir al villano ante el monarca «en demanda de justicia, bien para que este castigue al poderoso, que no ha sabido usar convenientemente su poder, bien para que corrobore la venganza que por su propia mano se ha tomado» (RUIZ RAMÓN, 2011: 154-155). Si el rey, reflejo divino en la tierra, amparaba al desfavorecido y salvaguardaba su honra, Jaime, protector de su familia y de sus vecinos, clama que la ejecución de Carlos no es más que la voluntad de Dios, que sanciona con sangre el comportamiento ruin de los burgueses. 


\section{REFERENCIAS BIBLIOGRÁFICAS}

Chevalier, Jean y Gheerbrant, Alain (1986): Diccionario de símbolos, Barcelona, Herder.

Chiachío Peláez, Amparo (2009): «La primera obra de un autor consagrado», Elucidario, 7 , pp. 183-199.

Cirlot, Juan Eduardo (1987): Diccionario de símbolos, Barcelona, Labor.

Cortés, Josep María: «El legado de los Sedó», La VANGUARDia, I I-IO-2009, PP. I 2-I3.

Cotarelo y Mori, Emilio (1928): «Editores y Galerías de obras dramáticas en Madrid en el siglo XIX», Revista de la Biblioteca, Archivo y Museo, 18, pp. 121-139.

Dicenta, JoAquín (1986): El señor feudal. Drama en tres actos y en prosa [Manuscrito]. Emp.: El teatro representa una finca propiedad (h. 2r)... Fin.: si puedes (h. 159r). Conservado en la Biblioteca del Instituto del Teatro.

- (1986): El señor feudal. Drama en tres actos y en prosa [Manuscrito]. Emp.: Deja tú que el sol te tueste (h. 3r)... Fin.: sálvalo, sálvalo si puedes (h. 150v). Conservado en la Biblioteca Nacional.

- (1986): El señor feudal. Drama en tres actos y en prosa, Madrid, Administración Lírico-Dramática.

— «Una carta de Dicenta», El Liberal, 30-01-1897, p. 1.

- (1910): Informe sobre reorganización de la enseñanza municipal de Madrid, Madrid, Imprenta Municipal.

- (1912): Los bárbaros, Madrid, Renacimiento.

— «El señor feudal, de Joaquín Dicenta, en el Aula de Teatro», ABC, 20-11-1963, p. 82.

EsE [seud. de Enrique Sepúlveda y Planter]: «Madrid teatral», La Correspondencia de España, 03-101896, p. 1.

Fernández Insuela, ANTONio (1997): «Sobre el nacimiento del teatro social español y su contexto», Monteagudo. Revista de Literatura Española, Hispanoamericana y Teoría de la literatura, 2, pp. 13-28.

- (1998): «Introducción» a Juan José, Madrid, Biblioteca Nueva, pp. 7-41.

- (2003): «Galdós y el drama social», Historia del teatro español. Del siglo XviII a la época actual, II, dir. Javier Huerta Calvo, Madrid, Gredos, pp. 2001-2030.

Filemón [seud. de Juan Tomás y Salvany]: «Dicenta y Paso», El Liberal, 10-07-1896, p. 2.

Forgas Berdet, Esther (1983): «Joaquín Dicenta: el autor y su obra bajo la perspectiva actual», Universitas Tarraconensis. Revista de Filología, 4, pp. 45-49.

GABALDón, Luis: «El señor feudal», Blanco y Negro, 19-12-1896, pp. 7-8.

García Pavón, Francisco (1962): El teatro social en España (1895-1962), Madrid, Taurus.

Gies, David T. (1996): El teatro en la España del siglo xIX, Cambridge, Cambridge University Press.

González Blanco, Andrés (1917): Los dramaturgos españoles contemporáneos, Valencia, Cervantes.

Gutiérrez Alonso, Francisco: «Un legado para el siglo XxI», Diario Sur, 15-11-2012, https://www. diariosur.es/v/20101115/cultura/legado-para-siglo-20101115.html, acceso 29-10-2021.

Gutiérrez Carbajo, Francisco (2003): «Alejandro Sawa: frustración literaria y anticlericalismo», Con Alonso Zamora Vicente: Actas del congreso internacional «la lengua, la Academia, lo popular, los clásicos, los contemporáneos», II, Coord. Carmen Alemany Bay et al., Alicante, Universidad, pp. 737-752.

Hall, H. B. (1952): «Joaquín Dicenta and the Drama of Social Criticism», Hispanic Review, XX, pp. 44-66.

Jiménez Morales, M. a IsABel (2020): «Spoliarium (1888), de Joaquín Dicenta: germen literario de su obra posterior», Anales de Literatura Española, 33, pp. 103-124.

López CRiado, Fidel (2011): «El teatro de Joaquín Dicenta: la otra revolución social», Arbor, CLXXXVII.752, pp.1197-1207.

Mas Ferrer, Jaime (1978): Vida, teatro y mito de Joaquín Dicenta, Alicante, Instituto de Estudios Alicantinos. 
McGrath, Leticia (2004): Joaquín Dicenta: Spain's Forgotten Dramatist, Delaware, Juan de la Cuesta.

Muñoz Álvarez, Manuel J. (2018): Estudio literario de «El señor feudal» (1896), entre el melodrama y la crítica, Trabajo de Fin de Grado, Universidad de Málaga. <https://hdl.handle. net/10630/16828>.

- (2020): «Evolución de una historia social en Joaquín Dicenta: análisis comparativo de 'El desquite' (1893), El señor feudal (1896) y Los bárbaros (1912)», Anales de Literatura Española, 33, pp. 141-162.

«Noticias y sucesos»: La Justicia, 7-10-1896, p. 2.

Paco de Moya, Mariano de (1971-1972): «El drama rural en España», Anales de la Universidad de Murcia, XXX.2, pp. 141-170.

Peral Vega, Emilio (2008): «Entre denuncia y melodrama: Juan José y el teatro social de Joaquín Dicenta», Revista de Literatura, LXX.139, pp. 67-84.

Pérez de la Dehesa, RAFAel (1970): El grupo Germinal: una clave del 98, Madrid, Taurus.

Ríos Carratalá, Juan A. (2019): «Joaquín Dicenta: 'Una calamidad nacional'», Anales de Literatura Española, 31, pp. 267-279.

Ruiz Ramón, Francisco (2011): Historia del teatro español. (Desde sus orígenes hasta 1900), Madrid, Cátedra.

Sancha Fernández, Eugénie (2015): El Teatro de la Comedia de Madrid (1875-1915): su historia y reconstrucción de la cartelera, Tesis Doctoral, UNED, Madrid. <http://e-spacio.uned.es/fez/view/ tesisuned:Filologia-Esancha>.

Simón Palmer, María del CARMen (1979): Manuscritos dramáticos de los siglos XVIII-XX de la Biblioteca del Instituto del Teatro de Barcelona, Barcelona, CSIC.

Solar y Taboada, Antonio del (1915): Don Narciso Díaz de Escovar (apuntes de su vida), Badajoz, Imprenta La Constancia.

Torrente Ballester, Gonzalo (1957): Teatro español contemporáneo, Madrid, Ediciones Guadarrama.

Trujillo, José Ramón (2015): «Retratos de mujer en la obra de Joaquín Dicenta», Creneida, 3, pp. 115-149 